\title{
RECOMMENDATIONS ON THE WORK WITH AUTHENTIC VIDEO MATERIALS IN FOREIGN LANGUAGE TEACHING
}

\author{
M.V. Kuimova ${ }^{1}$, H. Uzunboylu ${ }^{2}$, M.A. Golousenko ${ }^{1}$ \\ ${ }^{1}$ National Research Tomsk Polytechnic University, Tomsk, Russia \\ mkuimova@mail.ru \\ ${ }^{2}$ Near East University, Nicosia, Turkey
}

\begin{abstract}
Video is one of the most appreciated language teaching materials and well-liked by both teachers and learners. It brings variety and flexibility to the language classroom, gives a wide range of communicative situations, makes meaning clearer by providing visual clues (environment, dress, posture, gesture, facial expression, etc.) and communicates with viewers on an emotional as well as a cognitive level. Authentic video motivates learning interest and enthusiasm, improves students' language skills, and enhances comprehension and discussion. This paper discusses benefits, drawbacks, criteria for video selection and strategies to work with video. The authors give examples of exercises that can be used at foreign language classes.
\end{abstract}

Keywords: authentic video materials; cognitive activity; cultural awareness; foreign language skills; foreign language teaching; learning motivation; tolerance.

\section{Introduction}

The modern global market is looking for people with flexible intellectual skills, critical thinking, creativity, communication skills, lifelong curiosity and commitment. Nowadays, foreign language knowledge has become an essential component of a successful career prospect. To assure competitiveness of its alumni, universities introduce innovative teaching methods and techniques, information and communication technologies [1-10]. In this paper, we consider the use of authentic video in foreign language teaching.

\section{Background literature}

Application of authentic video in foreign language teaching provides a real familiarity with communication under particular conditions showing target language peculiarities including para- and extralinguistic means, emotion connotation and natural speech tempo. In addition, speech in an authentic environment improves language skills, and teaches another culture-specific concepts, body language, gestures, etc. Researchers note that watching video helps:

- motivate learning [11];

- promote a collaborative and more meaningful learning environment [12-14];

- create a communicative foreign language learning environment [15];

- gain new information in the target language and resolve problems related to the topic under study [16];

- improve pronunciation [17];

- foster communicative competence [18];

- reinforce grammar and extend vocabulary [19-20];

- enhance reading comprehension [21]. 
Moreover, the use of video in the classroom promotes individualization of learning and develops two types of motivation: self-motivation when the film is interesting in itself and motivation which is achieved by the fact that the student will be shown that he can understand the language under study. Furthermore, it brings satisfaction, gives confidence in their strength and desire to make further improvements.

\section{Findings and Discussion}

D. Gardner and L. Miller define authentic materials as materials intended for some other use except language learning [22]. Authentic materials in foreign language teaching ensure a number of benefits. They activate students' background knowledge of the world, give examples of real life communication in real situations and circumstances, show cultures different from one's own leading to tolerance of diverse lifestyles and customs, contribute language acquisition and help focus on the language skills students truly need [23-24].

Unlike an audio or printed text which can certainly be highly informative and educational $[10,25]$, video combines various speech aspects: content, visual information about places and events, appearance and non-verbal behavior of the participants in a given situation, often specified by age, gender and psychological characteristics of the speaking individuals [26]. Visual range allows better understanding and fixation of both factual information and purely linguistic features of speech in a particular context.

In addition, the use of video promotes the development of students' psychic activity, attention and memory. While viewing, there is an atmosphere of joint cognitive activity in the classroom. In these circumstances, even an inattentive pupil becomes attentive to understand the content of the video. So involuntary attention switches to voluntary and auditory, visual and motor perception positively affect the strength of memorizing cross-cultural and language material.

However, despite numerous advantages, authentic video materials may contain unfamiliar vocabulary items, complex language structures and may be too culturally biased. Thus, careful selection should be made according to the aims and objectives of the course. Selecting authentic video materials, the following criteria should be taken into account. They should:

- contain new and interesting information for students;

- demonstrate natural situations, characters and circumstances;

- contain contemporary language and meet the requirements and norms of the literary language of those areas which students often have to face (though, in many cases, the choice is determined by the objective of the lesson);

- have natural pauses between sentences;

- comply with students' age peculiarities, interests and their speech experience in native and foreign languages;

- the text should not be overloaded with new words, expressions and gestures of strangers;

- slang and colloquial expressions should be short enough and not too difficult for understanding;

- evoke emotional response.

Video becomes an effective means of language teaching when viewing is active. Traditionally tasks, to work with video, are divided into three stages:

1) before viewing (removal of language difficulties, determined by the communicative goal of viewing):

- read the video title, try to guess what can it be about; 
- read the video title, say what can its topic be? Say what you know/would like to know on this topic;

- read the list of words and try to determine the topic of the video; add other words connected with this topic;

- read the sentences and try to fill in the gaps with the maximum possible variants of nouns (verbs, adjectives, etc.);

- read the sentences and find the words that mean ...;

- read the sentences and find the tense which mean ...;

- read the sentences and write out verbs with preposition that mean motion (action period, time of action, etc.).

2) while viewing (students make notes and do tasks depending on the communicative task):

- video is played with sound and image, but at times the video is stopped and students try to guess what the characters say or do next;

- students watch video fragments and place the plan items in accordance with the logic of the fragment;

- video is stopped at key moments and students are asked to suggest what are the real thoughts of the speaker;

- working in groups, students write words that they associate with each of the characters and explain why, in their opinion, these words fit the character;

- name/enumerate the questions which are discussed in the video;

- watch the video and say which fragment is the most interesting for you and why?

- students watch part of the video. Then the video is shown without sound and students try to dub the video imitating tone, facial expressions and gestures of their characters;

- divide the class into groups. One group faces and watches the video with the sound turned off and retells the events to the group who was with their back to it. Then students switch places. Later the video is watched with the sound and students discuss the events together.

3) after viewing (oral and written tasks based on the video content):

- name the title that can be given to the video and explain why?;

- comment the following statements taken from the video;

- arrange the following questions in a sequence that corresponds to the video. Answer these questions;

- write questions to the video. Exchange the questions and answer them;

- using the video contents tell about ...;

- retell the jokes that you remember from the video;

- belie the opinion about ...;

- role-play the video situation about ...;

- compose the inner monologue/dialogue of the character/(s) based on their reactions, facial expressions, gestures, etc.;

- retell the video. Predict the categories of what could happen. Add information from books (newspapers, the Internet, your experience, etc.) to these categories;

- discuss the problem and ways of its solution using the video contents;

- discuss the video, relate the seen with real situations in your live, in your country and analyze the similarities and differences in culture;

- prepare a presentation about the main character(s) adding new information from 
newspapers/books/the Internet, etc.;

- role-play/write an alternative ending of the video;

- write a letter to the main character and give your recommendations;

- write the description about .... referred in the video.

Authentic video materials (taken from films, sitcoms, documentaries, cartoons, TV commercials, etc.) contribute cross-cultural awareness and understanding of other cultures, encourage students to see things from different perspectives, enlarge students' knowledge of the target language, improve listening skills, motivate communication and discussion, and serve as a basis for the development of writing skills (compositions, essays, reviews, etc). Video can be used at different stages of the lesson and with students of different age and educational levels. Of course, the most effective use of video is at an advanced stage, when students already have a certain amount of knowledge (vocabulary, grammar) and formed skills of independent work.

\section{Conclusion}

Thus, authentic video materials broaden horizons, simulate immersion in natural speech, further foreign language teaching, cultural awareness and another mentality in line with accepted and relied-upon speech standards. Another advantage is the strength of the movie experience and emotional impact on students, which affects the increase of motivation to the subject. It is necessary to strive to ensure that students receive the satisfaction of the viewing through the understanding of language and not only through an interesting and entertaining story line and connect the video topics to the curriculum and students' interests outside the class making the development of language skills more relevant.

\section{References:}

1. Richards J.C. (2013). Creativity in language teaching // Iranian Journal of Language Teaching Research, Volume 1, Issue 3, pp. 19-43.

2. Banditvilai C. (2016). Enhancing students' language skills through blended learning // Electronic Journal of e-Learning, Volume 14, Issue 3, pp. 220-229.

3. Greenfader C.M., Brouillette L. (2013). Boosting language skills of English learners through dramatization and movement // Reading Teacher, Volume 67, Issue 3, pp. 171-180. doi: 10.1002/TRTR.1192.

4. Kuimova M.V., Uzunboylu H., Startseva D.A., Devyatova K.P. (2016). Advantages of extracurricular drama activities in foreign language teaching // Ponte, Volume 72, Issue 6, pp. 52-56. doi: 10.21506/j.ponte.2016.6.4.

5. Kuimova M., Burleigh D., Trofimova A. (2016). Problem-based teaching in engineering education // MATEC Web of Conferences, Volume 48. http://dx.doi.org/10.1051/matecconf/20164806006.

6. Kuimova M.V., Karpacheva E.V. (2016). Game as a means to enhance foreign language teaching // Ponte, Volume 72, Issue 2. pp. 14-17. doi: 10.21506/j.ponte.2016.2.13.

7. Tarighat S., Khodabakhsh S. (2016). Mobile-Assisted Language Assessment: Assessing speaking // Computers in Human Behavior, Volume 64, pp. 409-413. doi: 10.5121/ijdps.2012.3126.

8. Kuimova M.V., Burleigh D.D., Arnst Yu.Yu., Sentsov A.E. (2016). Research activity as an integral component of engineering education // Ponte, Volume 72, Issue 4. pp. 127-131. doi: 10.21506/j.ponte.2016.4.19.

9. Ynuus M.M., Salehi H., Amini M., Shojaee M., Yun Fei W. (2016). Activities and suggestions for using social networking in teaching ESL writing // Journal of Theoretical and 
Applied Information Technology, Volume 84, Issue 2, pp. 170-182.

10. Kuimova M.V., Ukhov S.A. (2016). Some benefits of extracurricular reading in foreign language teaching // Ponte, Volume 72, Issue 4, pp. 276-280. doi: 10.21506/j.ponte.2016.4.39.

11. Miñano M.M.C., Grande E.U., Ezama D.P., Menéndez M.J.R. (2016). Multimedia teaching resources for financial accounting in bilingual degrees // Educacion XX1, Volume 19, Issue 1, pp. 63-90. doi: 10.5944/educXX1.13941.

12. Hameed P.F.M. (2016). Short films in the EFL classroom: Creating resources for teachers and learners // International Journal of Applied Linguistics and English Literature, Volume 5, Issue 2, pp. 215-219. doi:10.7575/aiac.ijalel.v.5n.2p.215.

13. De Luise D.L., Gelvez J., Borromeo N., Maguet L., Dima L. (2016). Multimedia as a tool for leaning engineering // Advances in Intelligent Systems and Computing. Volume 356, pp. 585-603.

14. Lan Y.-J., Chen N.-S., Sung Y.-T., Liu T.-C. (2015). Mind and body learn together: Embodied cognition and language learning // Proceedings - IEEE 15th International Conference on Advanced Learning Technologies: Advanced Technologies for Supporting Open Access to Formal and Informal Learning, ICALT 2015, pp. 469-471. doi: 10.1109/ICALT.2015.25.

15. Mehring J. (2016). Present Research on the Flipped Classroom and Potential Tools for the EFL Classroom // Computers in the Schools, Volume 33, Issue 1, pp. 1-10. doi: 10.1080/07380569.2016.1139912.

16. Dooly M., Sadler R. (2016). Becoming little scientists: Technologically-enhanced projectbased language learning // Language Learning and Technology, Volume 20, Issue 1, pp. 5478.

17. Nakai S., Beavan D., Lawson E., Leplâtre G., Scobbie J.M., Stuart-Smith J. (2016). Viewing speech in action: speech articulation videos in the public domain that demonstrate the sounds of the International Phonetic Alphabet (IPA) // Innovation in Language Learning and Teaching. doi:10.1080/17501229.2016.1165230.

18. Minaøíková E., Píŝová M., Janík T., Ulièná K. (2015). Video clubs: EFL teachers' selective attention before and after // Orbis Scholae, Volume 9, Issue 2, pp. 55-75. doi:10.14712/23363177.2015.80.

19. Cinganotto L., Cuccurullo D. (2015). The role of videos in teaching and learning content in a Foreign language // Journal of E-Learning and Knowledge Society. Volume 11, Issue 2, pp. 49-62.

20. Zhang Y., Jia W., Zhu C., Song Y. (2016). EVOV: A video recommendation system to support sustainable vocabulary learning // Proceedings of 2015 IEEE International Conference on Teaching, Assessment and Learning for Engineering, TALE 2015, pp. 43-48. doi: 10.1109/TALE.2015.7386013.

21. Huang Y.-H., Chuan T.-Y. (2016). Technology-assisted sheltered instruction: instructional streaming video in an EFL multi-purpose computer course // Computer Assisted Language Learning, Volume 29, Issue 3, pp. 618-637.

22. Gardner D., Miller L. (1999). Establishing self-access: From theory to practice. Cambridge: Cambridge University Press. 276 p.

23. Woottipong K. (2014). Effect of Using Video Materials in the Teaching of Listening Skills for University Students // International Journal of Linguistics, Volume 6, Issue 4, pp. 200-212. doi:10.5296/ijl.v6i4.5870.

24. López-Burton N., Minor D. (2014). On being a language teacher: A personal and practical guide to success. Book. 385 p. 
25. Kuimova M.V., Zvekov O.D. (2016). Blogs as a Means to Enhance Writing Skills in EFL Classes // iJET, Volume 11, Issue 4, pp. 157-160. http://dx.doi.org/10.3991/ijet.v11i04.5430. 26. Çakir I. (2006). The use of video as an audio-visual material in foreign language teaching classroom // TOJET, Volume 5, Issue 4. pp. 67-72. 